\title{
Hydroxytyrosol Decreases Phosphatidylserine Exposure and Inhibits Suicidal Death Induced by Lysophosphatidic Acid in Human Erythrocytes
}

\author{
Fabiana Tortora $^{\mathrm{a}}$ Rosaria Notariale ${ }^{\mathrm{a}}$ Florian Lang ${ }^{\mathrm{b}}$ Caterina Manna ${ }^{\mathrm{a}}$ \\ aDepartment of Precision Medicine, School of Medicine, University of Campania "Luigi Vanvitelli", \\ Naples, Italy, 'Department of Phamacology and Experimental Therapy, Eberhard-Karls-University of \\ Tuebingen, Tübingen, Germany
}

\section{Key Words}

Erythrocytes - Lysophosphatidic acid • Hydroxytyrosol • Phosphatidylserine • Cardiovascular diseases

\begin{abstract}
Background/Aims: Lysophosphatidic acid (LPA) is a phospholipid signal molecule that regulates many cellular processes both physiological and pathological. Moreover, its high plasma concentrations are toxic for several cellular types, including erythrocytes (RBC), as it acts as a pro-thrombotic and pro-atherogenic agent. It is therefore essential to explore the potential protective role of nutrition in protecting cells from the possible toxic effects of high plasma concentrations of LPA by testing bioactive nutrients. In particular, our focus was on hydroxytyrosol (HT), a phenolic antioxidant occurring naturally in virgin olive oil, investigating its possible protective effect in preventing LPA-induced programmed cell death (eryptosis) in human RBC. Methods: Intact RBC were incubated in the presence of $2.5 \mu \mathrm{M} \mathrm{LPA}$ and increasing concentrations of HT. Phosphatidylserine (PS) exposure with cell shrinkage, influx of extracellular calcium $\left(\mathrm{Ca}^{2+}\right)$, adenosine triphosphate (ATP) and glutathione levels were measured by FACS analysis. In addition, confocal laser scanning microscopy was used to determine RBC morphological alterations, as well as microvesicle formation. Results: Our study confirms that LPA-induced eryptosis is characterized by PS exposure at the cell surface, with cell shrinkage and ATP and glutathione depletion; $\left(\mathrm{Ca}^{2+}\right)$ influx is also a key event that triggers eryptosis. Here we report for the first time that cell co-incubation with LPA and in quantities as low as $0.1 \mu \mathrm{M} \mathrm{HT}$ causes a significant decrease in PS-exposing RBC, in addition to providing significant protection from the decrease in cell volume. Moreover, treatment of RBC with HT counters the influx of extracellular $\mathrm{Ca}^{2+}$ and completely restores ATP and glutathione content
\end{abstract}




\section{Cellular Physiology Cell Physiol Biochem 2019;53:921-932 \\ and Biochemistry $\begin{aligned} & \text { DOl: 10.33594/000000185 } \\ & \text { Published online: } 30 \text { November } 2019\end{aligned} \begin{aligned} & \text { O } 2019 \text { The Author(s). Published by } \\ & \text { Cell Physiol Biochem Press GmbH\&Co. KG }\end{aligned}$ \\ Tortora et al.: Hydroxytyrosol Prevents Lysophosphatidic Acid-Induced Eryptosis}

at $1 \mu \mathrm{M}$. Finally, under the same experimental conditions, HT exerts a protective effect on RBC morphological changes and microvescicle release, completely restoring the typical biconcave shape at $1 \mu \mathrm{M}$. Conclusion: Taken together, the findings reported in this paper point to a novel biological effect for $\mathrm{HT}$ in preventing programmed suicidal death in anucleated cells and indicate that prevention from LPA toxic effects may represent an additional mechanism responsible for the health-promoting effect of this dietary phenol which has been claimed, particularly related to cardiovascular diseases.

(C) 2019 The Author(s). Published by Cell Physiol Biochem Press GmbH\&Co. KG

\section{Introduction}

Lysophosphatidic acid (LPA) is an endogenous bioactive lipid, precursor in the biosynthesis of cellular phospholipids. In addition, LPA is an important extracellular signalling molecule and a second intracellular messenger [1, 2]. LPA performs various biological functions mainly via receptor-mediated mechanisms [2, 3]. These include, among others, the induction of platelet aggregation [4] and the regulation of embryonic growth and of blood pressure [2]. Furthermore, LPA also mediates many pathological processes, such as nephrotic diabetes [5], tumor progression [6] and various inflammatory processes [7], most notably of the skin [8].

Several mechanisms of LPA generation have been identified. In particular, its synthesis starts from membrane phospholipids through both extracellular and intracellular mechanisms. The enzyme phospholipase D, called autotaxin, which converts lysophosphatidylcholine into LPA is responsible for extracellular biosynthesis of this phospholipid [9]. LPA is also synthesized intracellularly in the endoplasmic reticulum and in the mitochondrial membrane, while several lipid phosphatases are in charge of LPA degradation [10]. LPA can be synthesized from various cell types, including fibroblasts, adipocytes and nerve cells following stimulation with cytokines or growth factors [11]. Moreover, thrombin-stimulated platelets also significantly contribute to LPA production [12]. Accordingly, serum LPA concentrations are higher than plasma. LPA is present in the plasma of healthy volunteers in the range of $0.14-1.64 \mu \mathrm{M}$ but its concentration increases about 10 fold in coagulated serum $[13,14]$. A higher concentration of up to $200 \mu \mathrm{M}$ has also been found in plasma and malignant ascites fluid in ovarian and cervical cancer patients $[15,16]$. The presence of LPA in plasma strongly influences all the hematic cellular types. Apart from the previously discussed effect on platelets, white cells are also responsive to LPA stimulation. LPA modulates monocytic cell migration directly and indirectly via its induced secretion of inflammatory cytokines [17]. Finally, the effects of LPA on erythrocytes (RBC) have also been reported in the literature. Chung et al. (2007) demonstrated that RBC respond to endogenous LPA expressing Phosphatidylserine (PS) on their surface, associated with severe morphological changes and the release of microvesicles (MV) [18].

The exposure of PS on the outer membrane leaflet of RBC serves as a signal for eryptosis, a mechanism responsible for the clearance of aged cells from blood circulation, [19] as well as anemia in some pathological conditions, including cancer [20]. Similar to apoptosis of nucleated cells, RBC may undergo programmed cell death, also called eryptosis [21-23]. The aim of this present study was to evaluate the possible protective effect against LPA-induced eryptosis exerted by hydroxytyrosol (HT), a bioactive dietary phenol, present in elevated concentrations in virgin olive oil [24-26]. As we have already reported in a previous paper, $\mathrm{HT}$ is able to counteract the metabolic alterations associated with eryptosis induced by the heavy metal mercury [27]. Intact human RBC were incubated in vitro in the presence of LPA and the protective effect of HT against eryptosis was evaluated by measuring several hallmarks including increase in PS exposure and intracellular calcium $\left(\mathrm{Ca}^{2+}\right)$, cell shrinkage, ATP and glutathione (GSH) depletion. Moreover, we also analyzed the protective effect of HT on changes in cell morphology of LPA-treated RBC, using confocal laser scanning microscope. 


\section{Cellular Physiology Cell Physiol Biochem 2019;53:921-932 \\ \begin{tabular}{l|l|l}
\hline DOI: 10.33594/000000185 & ( 2019 The Author(s). Published by
\end{tabular} \\ and Biochemistry Published online: 30 November 2019 Cell Physiol Biochem Press GmbH\&Co. KG \\ Tortora et al.: Hydroxytyrosol Prevents Lysophosphatidic Acid-Induced Eryptosis}

\section{Materials and Methods}

\section{Chemicals}

2',7'-dichlorodihydrofluorescein diacetate (DCFH-DA), LPA, and HT were from Sigma Chemical Co. Annexin V-FITC, Fluo-3/AM and 5-Chloromethylfluorescein diacetate (5- CMF) were from Immunotools (Friesoythe, Germany), Biotium (California,USA) and Santa Cruz Biotechnology (California,USA), respectively. All other chemicals used were of the purest grade available.

\section{Preparation and treatment of red blood cells}

Fresh Li-Heparin-anticoagulated blood samples were kindly provided by the blood bank of the University of Tübingen. The study is approved by the ethics committee of the University of Tübingen $(184 / 2003 \mathrm{~V})$. The blood was centrifuged at $120 \mathrm{~g}$ for $20 \mathrm{~min}$ at $21{ }^{\circ} \mathrm{C}$ and the platelets and leukocytescontaining supernatant were discarded. RBC were incubated in vitro at a hematocrit of $0.4 \%$ in Ringer solution containing (in $\mathrm{mM}$ ) $125 \mathrm{NaCl}, 5 \mathrm{KCl}, 1 \mathrm{MgSO} 4,32 \mathrm{~N}$-2-hydroxyethylpiperazine-N-2-ethanesulfonic acid (HEPES), 5 glucose, $1 \mathrm{CaCl}_{2}$; $\mathrm{pH} 7.4$ at $37^{\circ} \mathrm{C}$ for $4 \mathrm{~h}$. In nominally $\mathrm{Ca}^{2+}$-free solutions, $1 \mathrm{mM} \mathrm{CaCl}_{2}$ was replaced by $1 \mathrm{mM}$ Ethylene glycol-bis(2-aminoethylether)- $N, N, N^{\prime}, N^{\prime}$-tetraacetic acid (EGTA). RBC were coincubated at $37^{\circ} \mathrm{C}$ for $24 \mathrm{~h}$ with LPA $2.5 \mu \mathrm{M}$ and increasing concentrations of HT (0.1-1 $\left.\mu \mathrm{M}\right)$.

\section{Annexin-V-binding and forward scatter}

The percentage of annexin $\mathrm{V}$ and cell volume were determined as reported by Officioso et al. [27]. After incubation under respective experimental conditions, $100 \mu \mathrm{L}$ of RBC samples were washed in Ringer solution containing $5 \mathrm{mM} \mathrm{CaCl}_{2}$ and then stained with Annexin-V-FITC (1:200 dilution) in this solution at 37 ${ }^{\circ} \mathrm{C}$ for 20 min under protection from light. The annexin $\mathrm{V}$ abundance at the RBC surface was subsequently determined on a FACS Calibur (BD, Heidelberg, Germany). A dot plot of forward scatter (FSC) vs. side scatter (SSC) was set to linear scale for both parameters. The threshold of forward scatter was set at the default value of " 52 ".

\section{Assay system for hemolysis}

The extent of hemolysis was determined as previously described [27]. The samples were centrifuged at $1100 \mathrm{x} g$ for $5 \mathrm{~min}$ after incubation under the respective experimental conditions and the supernatants were harvested. As a measure of hemolysis, the hemoglobin concentration of the supernatant was determined photometrically at $405 \mathrm{~nm}$. The absorption of the supernatant of RBC lysed in distilled water was defined as $100 \%$ hemolysis.

\section{Intracellular calcium measurement}

The Fluo 3 fluorescence was conducted according to Officioso et al. [27]. After incubation, $100 \mu \mathrm{L}$ of RBC samples were washed in Ringer solution and then loaded with Fluo-3/AM in Ringer solution containing $5 \mathrm{mM}$ Fluo-3/AM. The cells were incubated at $37^{\circ} \mathrm{C}$ for $30 \mathrm{~min}$ and washed twice in Ringer solution containing $5 \mathrm{mM} \mathrm{CaCl}_{2}$. The Fluo-3/AM-loaded RBC were resuspended in $200 \mu \mathrm{L}$ Ringer. Then, $\mathrm{Ca}^{2+}$ dependent fluorescence intensity was measured with an excitation wavelength of $488 \mathrm{~nm}$ and an emission wavelength of $530 \mathrm{~nm}$ on a FACS Calibur.

\section{Determination of Reactive oxygen species}

Reactive oxygen species (ROS) formation was determined utilizing DCFH-DA as previously reported [27]. After incubation, a $100 \mu \mathrm{L}$ suspension of RBC was washed in Ringer solution and then stained with DCFH-DA at a final concentration of $10 \mu \mathrm{M}$. RBC were incubated at $37^{\circ} \mathrm{C}$ for $30 \mathrm{~min}$ in the dark and then washed three times in Ringer solution. The DCFH-DA-loaded RBC were resuspended in $200 \mu \mathrm{L}$ Ringer solution, and ROS-dependent fluorescence intensity was measured at an excitation wavelength of $488 \mathrm{~nm}$ and an emission wavelength of $530 \mathrm{~nm}$ on a FACS Calibur (BD).

\section{Intracellular ATP measurement}

The intracellular ATP content was evaluated utilizing a luciferin-luciferase assay kit (Roche Diagnostics). $80 \mu \mathrm{L}$ of RBC pellets were incubated for $24 \mathrm{~h}$ at $37^{\circ} \mathrm{C}$ in Ringer solution with LPA and HT. All subsequent manipulations were performed at $4{ }^{\circ} \mathrm{C}$ to avoid ATP degradation. Cells were lysed in distilled water, and 


\section{Cellular Physiology Cell Physiol Biochem 2019;53:921-932 \\ \begin{tabular}{l|l|l}
\hline DOI: 10.33594/000000185 & (c)19 The Author(s). Published by
\end{tabular} \\ and Biochemistry Published online: 30 November 2019 Cell Physiol Biochem Press GmbH\&Co. KG \\ Tortora et al.: Hydroxytyrosol Prevents Lysophosphatidic Acid-Induced Eryptosis}

proteins were precipitated by addition of $\mathrm{HClO}_{4}(5 \%)$. After centrifugation, an aliquot of the supernatant $(400 \mu \mathrm{L})$ was adjusted to $\mathrm{pH} 7.7$ by addition of saturated $\mathrm{KHCO}_{3}$ solution. After dilution of the supernatant, the ATP concentrations of the samples were determined measuring the bioluminescence, according to the manufacturer's protocol (Berthold Biolumat LB9500, Bad Wildbad, Germany).

\section{Quantification of intracellular Glutathione levels}

The measurement of cellular content of nonprotein thiols (glutathione) was made with $1 \mathrm{mM} 5$ - CMF dissolved in phosphate buffered saline pH 7.4 (PBS) 1x [28]. Briefly, after incubation under the respective experimental condition, $100 \mu \mathrm{L}$ of RBC samples were washed were centrifuged at $272 \mathrm{xg}$ for $3 \mathrm{~min}$ at $22^{\circ} \mathrm{C}$, the supernatant was discarded and the cells were stained with $5-\mathrm{CMF}$ at $37^{\circ} \mathrm{C}$ for 45 min under protection from light and washed once in PBS. Finally, $200 \mu \mathrm{L}$ PBS were added to the cells and GSH dependent fluorescence intensity was measured with an excitation wavelength of $488 \mathrm{~nm}$ and an emission wavelength of 510-530 nm on a FACS Calibur.

\section{Morphological analysis of erythrocytes}

To investigate the possible protective effect of HT on the alterations in the RBC shape induced by LPA, cells were co-incubated with $2.5 \mu \mathrm{M} \mathrm{HgCl}_{2}$ and $1 \mu \mathrm{M} \mathrm{HT}$ for $24 \mathrm{~h}$. After incubation, RBC were washed twice with PBS and counted in a Burker chamber. The Confocal Laser Scanning Microscope analyses were performed according to Nguyen et al. [29] with minor modifications. In brief, the cells were fixed with $2 \%$ formaldehyde for $1 \mathrm{~h}$ at $4^{\circ} \mathrm{C}$, washed several times with PBS, and then incubated with anti-human anti glycophorin A-FITC antibody for $30 \mathrm{~min}$ at $4^{\circ} \mathrm{C}$ in the dark. Afterwards, the samples were placed on glass slides and air-dried for $1 \mathrm{~h}$. For dehydration the slides were dipped quickly and gently washed stepwise with ethanol from 50 to $75,90,100 \%$ and then cells were fixed in $2 \%$ formaldehyde and finally washed three times with PBS. For Confocal Laser Scanning Microscope imaging, several randomly selected frames from each sample were captured for morphological observation and statistical strength. Excitation and emission filters were set at $488 \mathrm{~nm}$ and 550-600 $\mathrm{nm}$, respectively.

\section{Statistics}

Data were expressed as means \pm SEM. The significance of differences was determined by one-way ANOVA followed by a post hoc Tukey's multiple comparisons test. GraphPad Prism 5 was utilized for statistical analysis.

\section{Results}

Effect of LPA treatment on PS exposure and cell volume in RBC

In order to investigate the ability of HT to prevent LPA-induced programmed cell death in human RBC, intact cells were exposed for $24 \mathrm{~h}$ in vitro to increasing LPA concentrations and several markers of eryptosis were evaluated, including PS translocation towards the cell surface. PS exposure on the RBC membrane was identified by binding with annexin-V conjugated to a FITC fluorophore, as determined by flow cytometry. As reported in Fig. 1, and according to the data in the literature, exposure of the cells to LPA determines an increase in the percentage of annexin-V-binding RBC, reaching a statistically significant effect starting from a concentration of $1 \mu \mathrm{M}$ and reaching a $40 \%$ increase at $2.5 \mu \mathrm{M}$. Under the same experimental conditions, treatment with LPA induces a decrease in forward scattering RBC, indicating cell shrinkage, a phenomenon known to be associated with eryptosis.

\section{Effect of HT on LPA-induced PS exposure and cell volume in RBC}

Based on these results, we used 2.5 $\mu \mathrm{M}$ LPA to evaluate the possible protective effect of HT on eryptosis. Fig. 2 reports the dose-dependency of the effect of the phenolic compound on LPA-induced PS exposure. The treatment of RBC with increasing concentrations of HT significantly reduced the percentage of annexin-V-binding RBC in a dose- dependent manner, starting from very low concentrations such as $0.1 \mu \mathrm{M}$, and showing a complete protection at 
Fig. 1. Effect of LPA treatment on PS exposure and cell volume in RBC. Cells were treated in the presence of increasing concentrations of LPA. Original histogram of annexin-V-binding (A) and forward scatter (C) of RBC. Arithmetic means \pm SEM $(n=8)$ of annexin-V-binding (B) and forward scatter (D) of RBC. Data are the means \pm SEM $(n=8)$. Statistical significance was calculated by oneway ANOVA followed by Tukey's test. $*(\mathrm{p}<0.05)$ and $* *(\mathrm{p}<0.01)$ indicate a significant difference from cells lacking LPA treatment. For comparison, the effect of the solvent DMSO is shown (grey bar).

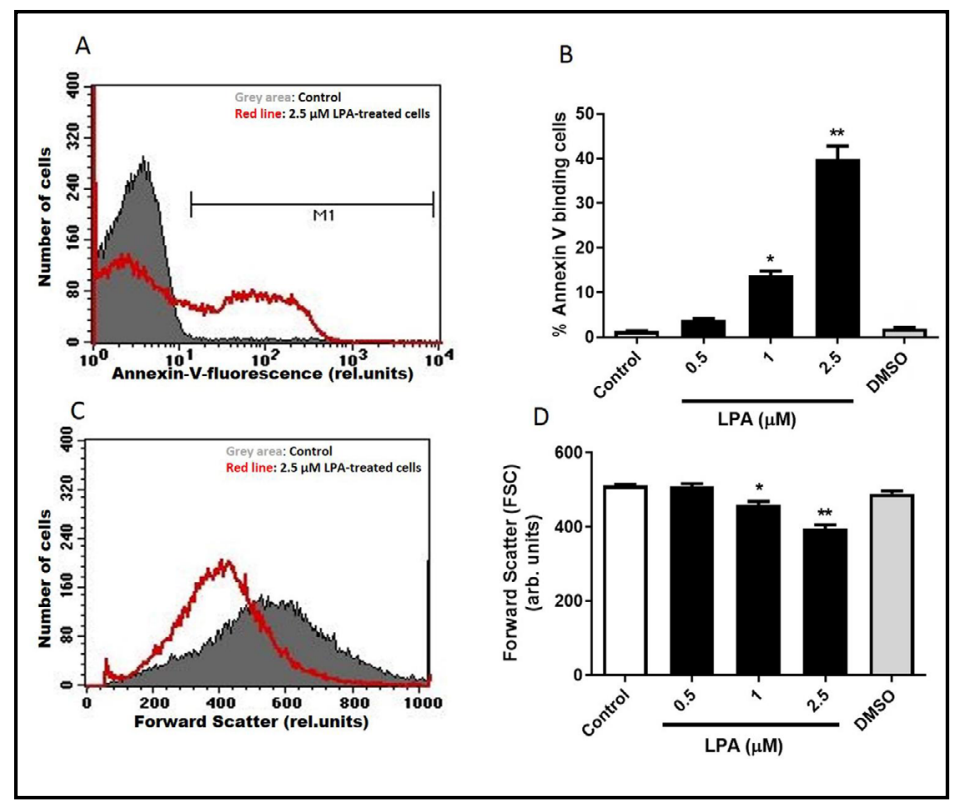

Fig. 2. Effect of HT on LPAinduced PS exposure and cell volume in RBC: Cells were treated with LPA for $24 \mathrm{~h}$ in the absence and presence of increasing concentrations of HT. Original histogram of annexin-V-binding (A) and forward scatter (C) of RBC. Arithmetic means \pm SEM $(n=8)$ of annexin-V-binding (B) and forward scatter (D) of RBC. Data are the means \pm SEM $(n=8)$. Statistical significance was calculated by one-way ANOVA followed by Tukey's test. ${ }^{* *}(\mathrm{p}<0.05)$ indicates a significant difference from cells lacking LPA treatment. \# (p $<0.05)$ and \#\# $(\mathrm{p}<0.01)$ indicate significant differences from cells

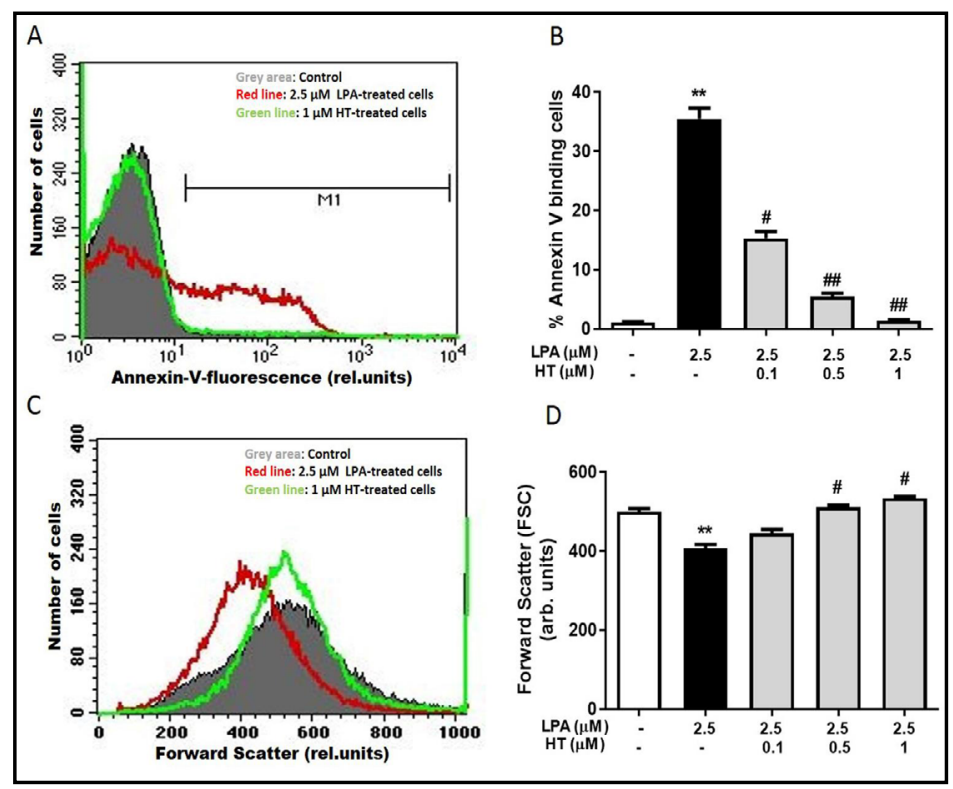
lacking HT treatment.

$1 \mu \mathrm{M}$. In the same concentration range, HT is also able to prevent the decrease in cell volume induced by LPA (Fig. 2).

\section{Effect of HT on intracellular $\mathrm{Ca}^{2+}$ in LPA-treated RBC}

The extracellular $\mathrm{Ca}^{2+}$ influx is considered a key event underlying the eryptotic process. Treatment with LPA induces an increase in the intracellular content of $\mathrm{Ca}^{2+}$, measured as Fluo3 fluorescence. Treatment of RBC with HT completely inhibits the extracellular $\mathrm{Ca}^{2+}$ influx at a concentration of $1 \mu \mathrm{M}$ (Fig. 3). 
Fig. 3. Effect of HT on intracellular $\mathrm{Ca}^{2+}$ in LPA-treated RBC: Cells were treated with LPA for $24 \mathrm{~h}$ in the absence and presence of increasing concentrations of HT. A. Original histogram of the Fluo 3 fluorescence of RBC. B. Arithmetic means \pm SEM $(n=8)$ of RBC. Statistical analysis was performed with one-way ANOVA followed by Tukey's test. ${ }^{*}(\mathrm{p}<0.05)$ indicates
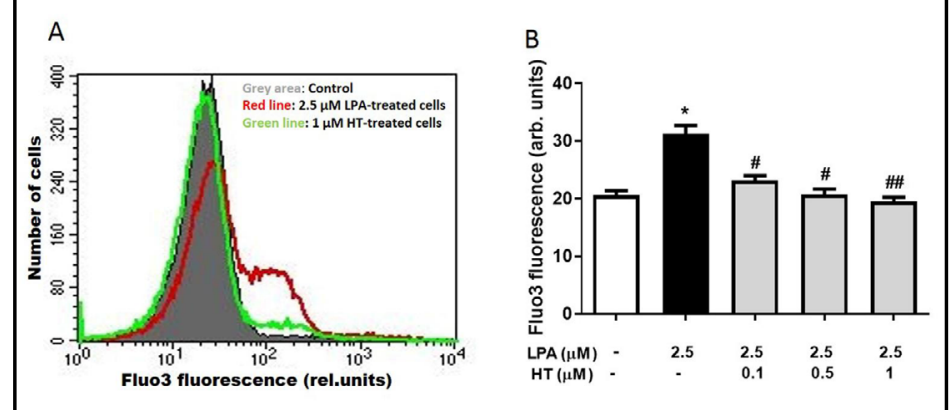
significant difference from the absence of LPA. \# ( $\mathrm{p}<0.05)$ and \#\# $(\mathrm{p}<0.01)$ indicate significant differences from cells lacking HT treatment.

Fig. 4. Effect of $\mathrm{HT}$ on $\mathrm{Ca}^{2+}$ sensitivity of LPA-induced PS exposure in RBC: Cells were treated with LPA for $24 \mathrm{~h}$ in the absence and presence of increasing concentrations of $\mathrm{HT}$ both in absence or presence of $\mathrm{Ca}^{2+} . \mathrm{B}, \mathrm{C}$. Original histogram of annexinV-binding in RBC. A. Arithmetic means \pm SEM $(n=8)$ of annexin-Vbinding of RBC. Statistical analysis was performed with one-way ANOVA followed by Tukey's test. * $(\mathrm{p}<0.05)$ and $* *(\mathrm{p}<0.01)$ indicate significant difference from the absence of LPA. \# $(\mathrm{p}<0.05)$ and \#\# $(\mathrm{p}<0.01)$ indicate significant differences from cells lacking HT

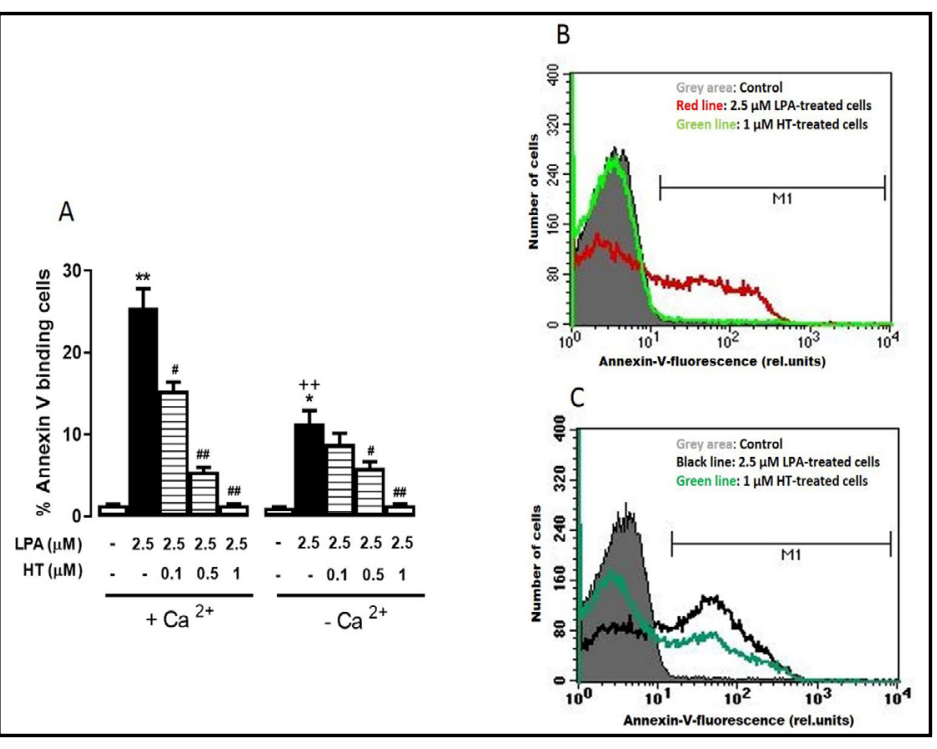
treatment. $++\quad(\mathrm{p}<0.05)$ indicates significant difference from corresponding value in the presence of $\mathrm{Ca}^{2+}$.

\section{Effect of $H T$ on $\mathrm{Ca}^{2+}$ sensitivity of LPA-induced PS exposure in $R B C$}

A series of experiments was then performed to further investigate the role of extracellular $\mathrm{Ca}^{2+}$ in LPA-induced PS exposure and the effect of HT. To this end, RBC were LPA-treated both in the absence and in the presence of extracellular $\mathrm{Ca}^{2+}$. Incubation of cells in the absence of extracellular $\mathrm{Ca}^{2+}$ drastically attenuated the effect of LPA on PS exposure (Fig. 4), confirming that the mechanisms underlying eryptosis are both Ca-dependent and Ca-independent. It is interesting to note that HT affects both mechanisms.

\section{Effect of HT on LPA-induced ATP depletion in RBC}

Eryptosis is also associated with energy depletion, as indicated by the decrease in intracellular ATP levels, following exposure of cells to LPA (Fig. 5). Cell treatment with $1 \mu \mathrm{M}$ HT completely restores the ATP levels of the control RBC.

\section{Effect of HT on LPA-induced GSH depletion in RBC}

To examine the relationship between LPA, cellular redox status and eryptosis, both cellular GSH content and ROS formation were evaluated. The data obtained indicate that treatment with LPA induces a significant depletion of GSH and that treatment with HT counteracts this depletion, restoring its basal levels at $1 \mu \mathrm{M}$ (Fig. 6). Under our experimental 
Fig. 5. Effect of HT on LPA-induced ATP depletion in RBC: Cells were treated with LPA for $24 \mathrm{~h}$ in the absence and presence of increasing concentrations of HT. Arithmetic means \pm SEM ( $n=$ 8) of cellular ATP of RBC. Statistical analysis was performed with one-way ANOVA followed by Tukey's test. * $(\mathrm{p}<0.05)$ indicates significant difference from the absence of LPA.\# $(\mathrm{p}<0.05)$ indicates significant difference from the absence of HT.

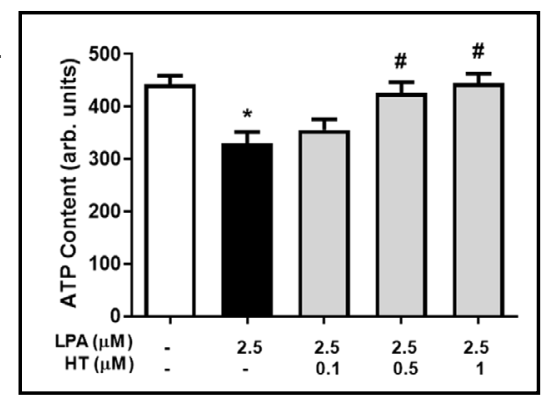

Fig. 6. Effect of HT on LPAinduced GSH depletion in RBC: Cells were treated with LPA for $24 \mathrm{~h}$ in the absence and presence of increasing concentrations of HT. A. Original histogram of 5-CMF of RBC. Arithmetic means \pm SEM $(n=8)$ of the 5 -CMF fluorescence of RBC. Statistical analysis was
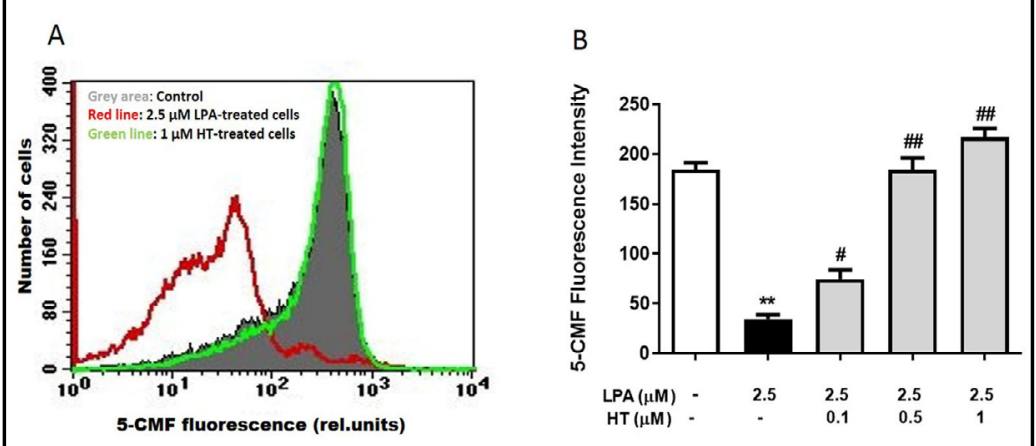
performed with one-way ANOVA followed by Tukey's test. ** $(\mathrm{p}<0.05)$ indicates significant difference from the absence of LPA. \# (p $<0.05)$ and \#\# ( $<<0.01)$ indicate significant differences from cells lacking HT treatment.

Fig. 7. Effect of HT on LPA-induced microvesicle release: Untreated cells are shown in (A). Cells were treated with 2.5 $\mu \mathrm{M}$ LPA for $24 \mathrm{~h}(\mathrm{~B})$ and concurrently treated with $1 \mu \mathrm{M}$ HT (C). RBC were stained with Annexin V-FITC.

conditions, no increase in ROS production was observed following exposure of RBC to LPA (data not shown).

Effect of HT on LPA-induced microvesicle release

To investigate the protective role of HT on RBC morphological changes and MV formation that are known to be induced by LPA treatment, cells were co-incubated with LPA and HT, as described in the section Materials and Methods, and analyzed with confocal microscopy. LPA treatment was associated with loss of the typical erythrocyte biconcave shape as well as the formation of MV, clearly discernible on cell membranes (not observable in the controls). Cell treatment with HT completely restores the typical biconcave shape at $1 \mu \mathrm{M}$ (Fig. 7).

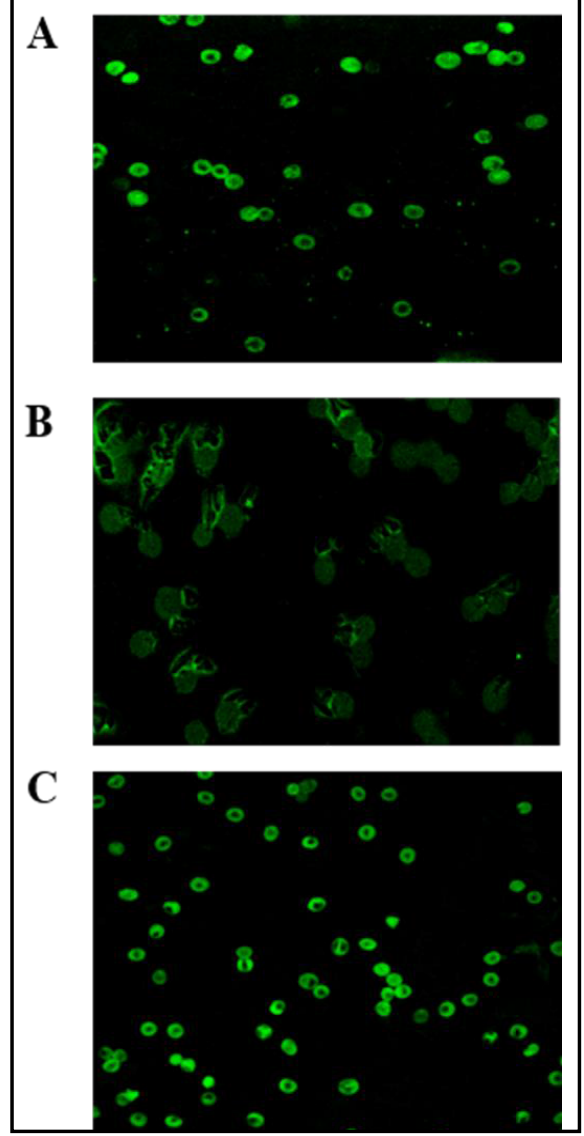




\section{Cellular Physiology Cell Physiol Biochem 2019;53:921-932 \\ \begin{tabular}{ll|l} 
and Biochemistry $10.33594 / 000000185$ & DO 2019 The Author(s). Published by \\
Published online: 30 November 2019 & Cell Physiol Biochem Press GmbH\&Co. KG
\end{tabular} \\ Tortora et al.: Hydroxytyrosol Prevents Lysophosphatidic Acid-Induced Eryptosis}

\section{Discussion}

LPA is not only a key metabolite in intracellular signalling but can also act as a potential endogenous toxic agent, as it can exacerbate inflammatory-related pathological conditions. It is therefore essential to explore new ways to protect cells from the possible toxic effects of high plasma LPA concentrations. In this regard, we considered that it was useful to verify the potential protective role of nutrition, by testing bioactive compounds normally present in our diet. Fruit and vegetables contain thousands of different phytochemicals, including polyphenols, some of which are able to strengthen biological functions with the aim of preventing and/or reducing the risk of diseases [30,31]. Among these our attention has focused on HT, the olive oil phenol which is endowed with important biological properties [24] and which significantly contributes to the positive effect of the Mediterranean Diet on human health mechanism responsible for the health-promoting effect of this dietary phenol which has been claimed [32, 33].

Intact human RBC were exposed to $2.5 \mu \mathrm{M}$ LPA and different markers of specific events and cellular toxicity were evaluated to test the protective effect of HT. Our study, in agreement with previous reports, confirms that LPA induces a suicidal death process in RBC through PS exposure at the cell surface, with a significant decrease in cell volume and energy depletion, associated with $\mathrm{Ca}^{2+}$ influx as well as a decrease in GSH content. Here we report for the first time experimental evidence of the efficacy of HT in preventing eryptosis in human RBC exposed in vitro to LPA treatment. Cell co-incubation with micromolar concentrations of HT and LPA causes a significant decrease in PS-exposing RBC, along with significant protection from the decrease in cell volume. Moreover, HT has countered the influx of extracellular $\mathrm{Ca}^{2+}$ and the decrease in cellular ATP. The protective effect of HT was further confirmed by microscopic observation of LPA-induced morphological changes. An interesting data is that HT is able to maintain cellular thiol homeostasis, counteracting GSH depletion in LPAexposed RBC. As far as mechanisms underlying the observed effect are concerned, this dietary phenol is endowed with strong scavenging activity. However, although ROS accumulation has been implicated as a relevant cofactor contributing to the cascade of events leading to programmed cell death, in our model system no increase in ROS production is observed (data not shown), indicating that HT biological activities, which are different from the scavenging potential, are involved in the protective effect. In this respect, according to our data and that reported in the literature [27, 34] GSH enhancement may play a key role. Finally, it should be emphasized that the experimental evidence reported in this study was observed at a physiologically relevant concentration of LPA, slightly above plasma level [13]. Moreover, the protective effect of HT was observed starting from a concentration as low as $0.1 \mu \mathrm{M}$, which may be approached in vivo upon strict adherence to the Mediterranean dietary pattern [32, 33 ] by a daily intake of 20-25 g of phenol-rich virgin olive oil [35, 36].

Taken together, the findings reported in this paper, in agreement with our previous data on eryptosis induced by $\mathrm{HgCl}_{2}$, point to a novel biological effect of $\mathrm{HT}$ in preventing programmed suicidal death in anucleated cells and indicate that prevention of the toxic effects of LPA may represent an additional mechanism responsible for the health-promoting effect of this dietary phenol, which has been claimed particularly related to Cardiovascular Diseases. As pointed out in the introduction, at a high concentration in the circulatory system, LPA can act as an endogenous atherogenic and thrombogenic molecule affecting the various phases of the complex process of coagulation and plaque formation [37-39]. Of possible pathophysiologic relevance is the LPA-induced platelet-monocyte aggregation in whole blood [40], which is considered an early event of acute myocardial infarction. The adherence of platelets to monocytes stimulates in these cells the expression of tissue factor, promotes fibrin formation, thus accelerating intravascular thrombosis. Moreover, in a recent paper, Ray and Rai reveal that LPA converts monocytes into macrophages in both mice and humans [41].

LPA is also an important factor favouring endothelial dysfunctions involved in the progression of atherosclerosis. LPA enhanced IL-8 and monocyte chemoattractant 


\section{Cellular Physiology Cell Physiol Biochem 2019;53:921-932

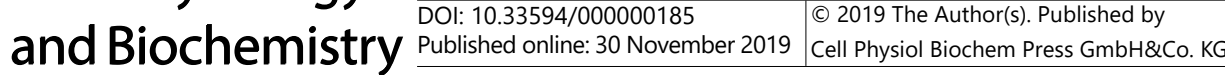

protein-1 (MCP-1) expression in human umbilical vein endothelial cells [42] and stimulate the production of adhesion molecules on the cell surface, favoring monocyte-endothelial interactions, both key steps in the onset of the early atherosclerotic lesion [43, 44]. Moreover, LPA-induction of foam cells formation and oxidized low density lipoproteins (oxLDL) uptake in J774 macrophages have been reported $[45,46]$. Interestingly, LPA concentration is particularly high in the atherosclerotic plaques, mainly bound to oxLDL [39]. In this respect it has been proposed that, following plaque rupture $[47,48]$, LPA accumulated in the lipidrich core in the intima of the arterial wall may trigger platelet activation, thus contributing to thrombosis.

As indicated in the introduction, RBC can also be significantly modified by LPA, thus acquiring a pro-coagulant and thrombogenic activity. As clearly highlighted in a recent review by Weisel and Litvinov, RBC represent "a forgotten player in hemostasis and thrombosis" [49]. Beside the well-known role of platelets in blood coagulation, an increasing quantity of data has revealed that RBC metabolic and/or morphological alterations can play a clinically significant role in this pathophysiological process, mainly related to PS exposure [50] on the cell surface and PS-exposing MV formation. PS, an essential component of blood clotting, is normally located in the inner leaflet of the plasma membrane and its exposure on the cell surface provides a matrix for assembly of plasma coagulation factors. Accordingly, both the PS-bearing remnant cells and MV isolated from LPA-treated RBC actually potentiated prothrombinase activity, associated with increased thrombin generation in plasma [18]. Besides, after in vitro exposure of RBC to LPA, remnants of RBC showed enhanced adherence to endothelial cells [18] while MV can accelerate blood clotting [49] therefore promoting occlusion of microvasculature, associated with thrombotic events [29, 51]. Finally, an intracellular adhesion of RBC exposed to LPA have been reported [52].

Taken together, the reported literature data strongly indicate that LPA is a potential risk factor for Cardiovascular Diseases. In this respect, in a pilot study Cun-Shan et al. [53] found that people with one or two risk factors, namely hypertension and hyperlipidemia, tend to have higher plasma LPA levels compared to controls. Moreover, serum LPA levels have been reported to increase more than twofold in patients with acute myocardial infarction [54] and to increase in patients with acute coronary syndrome compared to both controls and patients with stable angina pectoris [55], confirming the involvement of LPA in the pathophysiology of the cardiovascular system.

\section{Conclusion}

Many pharmacological approaches have been designed for the prevention and treatment of LPA-related clinical outcomes, keeping as targets the enzymes of its synthesis and degradation as well as the LPA agonists [56-58]. The novel beneficial property reported in this paper regarding the efficacy of HT to reduce the LPA-induced metabolic as well as morphological alterations in human RBC opens a new horizon for innovative therapeutic interventions to prevent thrombotic events in the setting of atherosclerosis and provides a biochemical base for the use of bioactive nutrients-based functional foods or pharmacological preparations. In this respect HT, which is endowed with a broad spectrum of biological activity including anti-inflammatory, anti-atherogenic and anti-thrombotic properties demonstrated in several different model systems, appears as a promising candidate.

\section{Abbreviations}

5-CMF (5-Chloromethylfluorescein diacetate); ATP (Adenosine triphosphate); DCFHDA (2',7'-Dichlorodihydrofluorescin diacetate); FSC (Forward scatter); GSH (Glutathione); HT (Hydroxytyrosol); LPA (Lysophosphatidic acid); MV (Microvesicles); oxLDL (Oxidized 


\section{Cellular Physiology Cell Physiol Biochem 2019;53:921-932 \\ \begin{tabular}{l|l|l}
\hline DOI: 10.33594/000000185 & (c)19 The Author(s). Published by
\end{tabular} \\ and Biochemistry Published online: 30 November 2019 Cell Physiol Biochem Press GmbH\&Co. KG \\ Tortora et al.: Hydroxytyrosol Prevents Lysophosphatidic Acid-Induced Eryptosis}

low density lipoproteins); PBS (Phosphate-buffered saline); PS (Phosphatidylserine); RBC (Red blood cells); ROS (Reactive oxygen species); SSC (Side scatter).

\section{Acknowledgements}

This research received no external funding.

\section{Disclosure Statement}

All authors declare that there are no conflicts of interest that could be perceived as prejudicing the impartiality of the research reported.

\section{References}

1 Aikawa S, Hashimoto T, Kano K, Aoki J: Lysophosphatidic acid as a lipid mediator with multiple biological actions. J Biochem 2015;157:81-89.

2 Sheng X, Yung YC, Chen A, Chun J: Lysophosphatidic acid signalling in development. Development 2015;142:1390-1395.

3 Choi JW, Herr DR, Noguchi K, Yung YC, Lee CW, Mutoh T, Lin ME, Teo ST, Park KE, Mosley AN, Chun J: LPA receptors: subtypes and biological actions. Annu Rev Pharmacol Toxicol 2010;50:157-186.

4 Retzer M, Essler M: Lysophosphatidic acid-induced platelet shape change proceeds via Rho/Rho kinasemediated myosin light-chain and moesin phosphorylation. Cell Signal 2000;12:645-648.

5 Lee JH, Kim D, Oh YS, Jun HS: Lysophosphatidic Acid Signaling in Diabetic Nephropathy Int J Mol Sci 2019;20:2850-2865

6 Valdés-Rives SA, González-Arenas A: Autotaxin-Lysophosphatidic Acid: From Inflammation to Cancer Development. Mediators Inflamm 2017;2017:9173090.

7 Lin CI, Chen CN, Lin PW, Chang KJ, Hsieh FJ, Lee H: Lysophosphatidic acid regulates inflammation-related genes in human endothelial cells through LPA1 and LPA3. Biochem Biophys Res Commun 2007;363:10011008.

8 Lei L, Su J, Chen J, Chen W, Chen X, Peng C: The role of lysophosphatidic acid in the physiology and pathology of the skin. Life Sci 2019;220:194-200.

9 Nakanaga K, Hama K, Aoki J: Autotaxin--an LPA producing enzyme with diverse functions. J Biochem 2010;148:13-24.

10 Mazereeuw-Hautier J, Gres S, Fanguin M, Cariven C, Fauvel J, Perret B, Chap H, Salles JP, Saulnier-Blache J-S: Production of lysophosphatidic acid in blister fluid: involvement of a lysophospholipase D activity. J Invest Dermatol 2005;125:421-427.

11 Kalari S, Zhao Y, Spannhake EW, Berdyshev EV, Natarajan V: Role of acylglycerol kinase in LPA-induced IL-8 secretion and transactivation of epidermal growth factor-receptor in human bronchial epithelial cells. Am J Physiol Lung Cell Mol Physiol 2009;296:L328-336.

12 Eichholtz T, Jalink K, Fahrenfort I, Moolenaar WH: The bioactive phospholipid lysophosphatidic acid is released from activated platelets. Biochem J 1993;291:677-680.

13 Michalczyk A, Budkowska M, Dołęgowska B, Chlubek D, Safranow K: Lysophosphatidic acid plasma concentrations in healthy subjects: circadian rhythm and associations with demographic, anthropometric and biochemical parameters. Lipids Health Dis 2017;16:140-149.

14 Siess W: Athero- and thrombogenic actions of lysophosphatidic acid and sphingosine-1-phosphate. Biochim Biophys Acta 2002;1582:204-215.

15 Meleh M, Pozlep B, Mlakar A, Meden-Vrtovec H, Zupancic-Kralj L: Determination of serum lysophosphatidic acid as a potential biomarker for ovarian cancer. J Chromatogr B 2007;858:287-291.

16 Bese T, Barbaros M, Baykara E, Guralp O, Cengiz S, Demirkiran F, Sanioglu C, Arvas M: Comparison of total plasma lysophosphatidic acid and serum CA-125 as a tumor marker in the diagnosis and follow-up of patients with epithelial ovarian cancer. J Gynecol Oncol 2010;21:248-254. 


\section{Cellular Physiology Cell Physiol Biochem 2019;53:921-932 \begin{tabular}{ll|l}
\hline DOI: 10.33594/000000185 & (c)19 The Author(s). Published by
\end{tabular} and Biochemistry Published online: 30 November 2019 Cell Physiol Biochem Press GmbH\&Co. KG

17 Gustin C, Van Steenbrugge M, Raes M: LPA modulates monocyte migration directly and via LPA-stimulated endothelial cells. Am J Physiol Cell Physiol 2008;295:C905-914.

18 Chung SM, Bae ON, Lim KM, Noh JY, Lee MY, Jung YS, Chung JH: Lysophosphatidic acid induces thrombogenic activity through phosphatidylserine exposure and procoagulant microvesicle generation in human erythrocytes. Arterioscler Thromb Vasc Biol 2007;27:414-421.

19 Wesseling MC, Wagner-Britz L, Huppert H, Hanf B, Hertz L, Nguyen DB, Bernhardt I: Phosphatidylserine Exposure in Human Red Blood Cells Depending on Cell Age. Cell Physiol Biochem 2016;38:1376-1390.

20 Bissinger R, Schumacher C, Qadri SM, Honisch S, Malik A, Götz F, Kopp HG, Lang F: Enhanced eryptosis contributes to anemia in lung cancer patients. Oncotarget 2016;7:14002-14014.

21 Lang F, Qadri SM: Mechanisms and significance of eryptosis, the suicidal death of erythrocytes. Blood Purif 2012;33:125-130.

22 Officioso A, Alzoubi K, Manna C, Lang F: Clofazimine Induced Suicidal Death of Human Erythrocytes. Cell Physiol Biochem 2015;37:331-341.

23 Officioso A, Manna C, Alzoubi K, Lang F: Triggering of Erythrocyte Death by Triparanol. Toxins (Basel) 2015;7:3359-3371.

24 Echeverría F, Ortiz M, Valenzuela R, Videla LA: Hydroxytyrosol and Cytoprotection: A Projection for Clinical Interventions. Int J Mol Sci 2017;18:930-944.

25 Rodríguez-Morató J, Xicota L, Fitó M, Farré M, Dierssen M, de la Torre R: Potential role of olive oil phenolic compounds in the prevention of neurodegenerative diseases. Molecules 2015;20:4655-4680.

26 Officioso A, Panzella L, Tortora F, Alfieri ML, Napolitano A, Manna C: Comparative Analysis of the Effects of Olive Oil Hydroxytyrosol and Its 5-S-Lipoyl Conjugate in Protecting Human Erythrocytes from Mercury Toxicity. Oxid Med Cell Longev 2018;2018:9042192.

27 Officioso A, Alzoubi K, Lang F, Manna C: Hydroxytyrosol inhibits phosphatidylserine exposure and suicidal death induced by mercury in human erythrocytes: Possible involvement of the glutathione pathway. Food Chem Toxicol 2016;89:47-53.

28 Ueha-Ishibashi T, Tatsuishi T, Iwase K, Nakao H, Umebayashi C, Nishizaki Y, Nishimura Y, Oyama Y, Hirama S, Okano Y: Property of thimerosal-induced decrease in cellular content of glutathione in rat thymocytes: a flow cytometric study with 5-chloromethylfluorescein diacetate. Toxicol In Vitro 2004;18:563-569.

29 Nguyen DB, Ly TBT, Wesseling MC, Hittinger M, Torge A, Devitt A, Perrie Y, Bernhardt I: Characterization of Microvesicles Released from Human Red Blood Cells. Cell Physiol Biochem 2016;38:1085-1099.

30 Casas R, Estruch R, Sacanella E: Influence of Bioactive Nutrients on the Atherosclerotic Process: A Review. Nutrients 2018;10:1630-1656.

31 Gorzynik-Debicka M, Przychodzen P, Cappello F, Kuban-Jankowska A, Marino Gammazza A, Knap N, Wozniak M, Gorska-Ponikowska M: Potential Health Benefits of Olive Oil and Plant Polyphenols Int J Mol Sci 2018;19:547-560.

32 Martínez-González MA, Salas-Salvadó J, Estruch R, Corella D, Fitó M, Ros E: Benefits of the Mediterranean Diet: Insights From the PREDIMED Study. Prog Cardiovasc Dis 2015;58:50-60.

33 Gerber M, Hoffman R: The Mediterranean diet: health, science and society. Br J Nutr 2015;113:S4-S10.

34 Mohan V, Das S, Rao SBS: Hydroxytyrosol, a dietary phenolic compound forestalls the toxic effects of methylmercury-induced toxicity in IMR-32 human neuroblastoma cells. Environ Toxicol 2016;31:12641275.

35 Pastor A, Rodríguez-Morató J, Olesti E, Pujadas M, Pérez-Mañá C, Khymenets O, Fitó M, Covas MI, Solá R, Motilva MJ, Farré M, de la Torre R: Analysis of free hydroxytyrosol in human plasma following the administration of olive oil. J Chromatogr A 2016;1437:183-190.

36 Miro-Casas E, Covas MI, Farre M, Fito M, Ortuño J, Weinbrenner T, Roset P, de la Torre R: Hydroxytyrosol disposition in humans. Clin Chem 2003;49:945-952.

37 Zhao Y, Hasse S, Zhao C, Bourgoin SG: Targeting the autotaxin - Lysophosphatidic acid receptor axis in cardiovascular diseases. Biochem Pharmacol 2019;164:74-81.

38 Abdel-Latif A, Heron PM, Morris AJ, Smyth SS: Lysophospholipids in coronary artery and chronic ischemic heart disease. Curr Opin Lipidol 201526:432-437.

39 Schober A, Siess W: Lysophosphatidic acid in atherosclerotic diseases. Br J Pharmacol 2012;167:465-482.

40 Haserück N, Erl W, Pandey D, Tigyi G, Ohlmann P, Ravanat C, Gachet C, Siess W: The plaque lipid lysophosphatidic acid stimulates platelet activation and platelet-monocyte aggregate formation in whole blood: involvement of P2Y1 and P2Y12 receptors. Blood 2004;103:2585-2592. 


\section{Cellular Physiology Cell Physiol Biochem 2019;53:921-932 \begin{tabular}{c|l} 
DOI: 10.33594/000000185 & (c) 2019 The Author(s). Published by
\end{tabular} and Biochemistry Published online: 30 November 2019 Cell Physiol Biochem Press GmbH\&Co. KG \\ Tortora et al.: Hydroxytyrosol Prevents Lysophosphatidic Acid-Induced Eryptosis}

41 Ray R, Rai V: Lysophosphatidic acid converts monocytes into macrophages in both mice and humans. Blood 2017;129:1177-1183.

42 Lin CI, Chen CN, Chen JH, Lee H: Lysophospholipids increase IL-8 and MCP-1 expressions in human umbilical cord vein endothelial cells through an IL-1-dependent mechanism. J Cell Biochem 2006;99:12161232.

43 Rizza C, Leitinger N, Yue J, Fischer DJ, Wang DA, Shih PT, Lee H, Tigyi G, Berliner JA: Lysophosphatidic acid as a regulator of endothelial/leukocyte interaction. Lab Invest 1999;79:1227-1235.

44 Cui MZ: Lysophosphatidic acid effects on atherosclerosis and thrombosis. Clin Lipidol 2011;6:413-426.

45 Chang CL, Hsu HY, Lin HY, Chiang W, Lee H: Lysophosphatidic acid-induced oxidized low-density lipoprotein uptake is class A scavenger receptor-dependent in macrophages. Prostaglandins Other Lipid Mediat 2008;87:20-25.

46 Chen L, Zhang J, Deng X, Liu Y, Yang X, Wu Q Yu C: Lysophosphatidic acid directly induces macrophagederived foam cell formation by blocking the expression of SRBI. Biochem Biophys Res Commun 2017;491:587-594.

47 Gu C, Wang F, Zhao Z, Wang H, Cong X, Chen X: Lysophosphatidic Acid Is Associated with Atherosclerotic Plaque Instability by Regulating NF- $\kappa$ B Dependent Matrix Metalloproteinase-9 Expression via LPA2 in Macrophages. Front Physiol 2017;8:266.

48 Siess W, Zangl KJ, Essler M, Bauer M, Brandl R, Corrinth C, Bittman R, Tigyi G, Aepfelbacher M: Lysophosphatidic acid mediates the rapid activation of platelets and endothelial cells by mildly oxidized low density lipoprotein and accumulates in human atherosclerotic lesions. Proc Natl Acad Sci USA 1999;96:6931-6936.

49 Weisel JW, Litvinov RI: Red blood cells: the forgotten player in hemostasis and thrombosis. J Thromb Haemost 2019;17:271-282.

50 Arashiki N, Takakuwa Y: Maintenance and regulation of asymmetric phospholipid distribution in human erythrocyte membranes: implications for erythrocyte functions. Curr Opin Hematol 2017;24:167-172.

51 Wesseling MC, Wagner-Britz L, Nguyen DB, Asanidze S, Mutua J, Mohamed N, Hanf B, Ghashghaeinia M, Kaestner L, Bernhardt I: Novel Insights in the Regulation of Phosphatidylserine Exposure in Human Red Blood Cells. Cell Physiol Biochem 2016;39:1941-1954.

52 Kaestner L, Steffen P, Nguyen DB, Wang J, Wagner-Britz L, Jung A, Wagner C, Bernhardt I: Lysophosphatidic acid induced red blood cell aggregation in vitro. Bioelectrochemistry 2012;87:89-95.

53 Yao CS, Yan SG, Gao LS, Sun ZR, Liu F, Jiang B, Wang HB, Wu QZ: Patients with risk factors have higher plasma levels of lysophosphatidic acid: a promising surrogate marker for blood platelet activation. Blood Coagul Fibrinolysis 2014;25:322-325.

54 Chen X, Yang XY, Wang ND, Ding C, Yang YJ, You ZJ, Su Q, Chen JH: Serum lysophosphatidic acid concentrations measured by dot immunogold filtration assay in patients with acute myocardial infarction. Scand J Clin Lab Invest 2003;63:497-503.

55 Dohi T, Miyauchi K, Ohkawa R, Nakamura K, Kishimoto T, Miyazaki T, Nishino A, Nakajima N, Yaginuma K, Tamura H, Kojima T, Yokoyama K, Kurata T, Shimada K, Yatomi Y, Daida H: Increased circulating plasma lysophosphatidic acid in patients with acute coronary syndrome. Clin Chim Acta 2012;413:207-212.

56 Zhou Y, Little PJ, Ta HT, Xu S, Kamato D: Lysophosphatidic acid and its receptors: pharmacology and therapeutic potential in atherosclerosis and vascular disease. Pharmacol Ther 2019; DOI:10.1016/j. pharmthera.2019.107404.

57 Matralis AN, Afantitis A, Aidinis V: Development and therapeutic potential of autotaxin small molecule inhibitors: From bench to advanced clinical trials. Med Res Rev 2019;39:976-1013.

58 Ninou I, Kaffe E, Müller S, Budd DC, Stevenson CS, Ullmer C, Aidinis V: Pharmacologic targeting of the ATX/ LPA axis attenuates bleomycin-induced pulmonary fibrosis. Pulm Pharmacol Ther 2018;52:32-40. 